\title{
CHYLOUS ASCITES IN INFANCY
}

\author{
BY \\ I. KESSEL \\ From the Department of Paediatrics, Baragwanath Hospital and the University of the Witwatersrand, \\ Johannesburg, South Africa
}

(RECEIVED FOR PUBLICATION APRII 27, 1951)

Chylous effusions into serous cavities are interesting occurrences especially as they affect infants. A milky effusion into the peritoneal cavity is extremely rare in early life. Wallis and Schölberg (1911) collected 173 cases of milky ascites in all age groups. Of these only three occurred in infants under 1 year of age. Witt (1924) mentions 187 cases recorded between 1691 and 1916 of which only 29 occurred in children. In 1922 two further cases were recorded by Scherer and by Schall, both in infants under 1 year. Of this total of 31 cases in children, nine were under 1 year of age, eight occurred between the ages of 1 and 5 years, and the remaining 14 were in the age group 5 to 12 . The youngest, a neonate of 16 days, was reported by Kerr (1909). The original collection of 53 cases of chylous ascites, occurring in all age groups, and covering the period 1699-1889, was recorded by Busey (1889). Cowie (1911) collected eight cases of this affection in infants and added one of his own. Five of these were under the age of 12 months and the remaining four were in the age group 12 to 32 months. Cowie's series includes the first case ever reported, that of Morton (1691). This case was recorded in Latin and translated for Cowie by Professor Meader: the patient was a boy of 2 years, and the description mentions 'a distended abdomen which increased daily'. The child developed 'a severe marasmus' but 'retained a robust and handsome appearance'. ' His appetite was substantial, if anything inclined to voraciousness, up to the very day of his death. From these acute observations Morton correctly concluded that the ascites was chylous and that the inanition resulted from 'the withdrawal of the nutritious fluid due to the body, from the chyliferous ducts'. The abdomen was tapped and 'several pounds of lactescent chyle, just as sweet as is found in the chyle duct itself' were removed. The necropsy findings in this case suggested tuberculosis as the causative factor.
Nieuwondt and Rozenzweig (1892) described a case from Cape Town, South Africa, that of a girl of 15 months of age from whom $20,400 \mathrm{ml}$. of milky fluid were tapped from the peritoneal cavity on 11 occasions. The fluid had a specific gravity of 1012 , was neutral, white and creamy, and had a sweetish odour. The authors considered that the fluid only slightly resembled the general character of chyle, and that the condition was due to attacks of peritonitis. Kerr's (1909) case was a boy aged 16 days. In this child $1,140 \mathrm{ml}$. of a milky-white, odourless fluid were removed. The cause was given as congenital syphilis, and the abdominal distension was associated with chyluria.

\section{Case Report}

A Bantu girl aged 11 weeks was admitted to hospital under my care on November 8,1950. The diagnosis of the admitting officer was 'abdominal distension'. The history given by the mother was that the child had been born in a maternity hospital and had been "swollen" from birth. The mother herself had had toxaemia of pregnancy and remained in the hospital for 23 days after confinement. She stated that the swelling of the child had subsided by the time she left the maternity centre, except for the abdomen, which became progressively larger. The infant was breast-fed and there was no abnormality in the bowel actions or micturition. There was one other child in the family; he was healthy, as was the father.

The infant appeared to be a fairly well-nourished, contented child. On admission the weight was $11 \mathrm{lb}$., and the temperature $98 \cdot 4^{\circ} \mathrm{F}$. (rectal).

The head was normal in size and shape. The throat appeared normal, as did the ear-drums. There were no palpable glands in any area. Nothing abnormal was detected in the cardiovascular, respiratory or nervous systems. Examination of the abdomen revealed marked distension. Dilated veins were seen on the anterior abdominal wall. Shifting dullness was present and a fluid thrill was easily felt. The external genitalia appeared to be swollen and there was a left inguinal hernia. On 
account of the marked distension of the abdomen no organs could be felt. Rectal examination did not reveal any abnormality.

There was obviously a large amount of fluid in the peritoneal cavity and paracentesis was performed on the day after admission, $26 \mathrm{oz}$. of a white fluid similar to milk being removed. It was clear that this was probably a case of chylous ascites.

Analysis of the fluid showed:

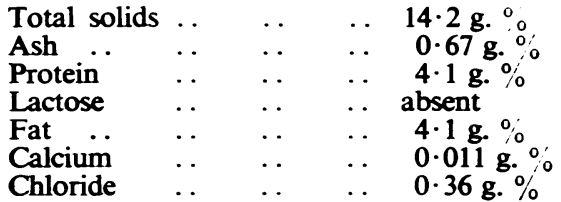

The cholesterol content of the fluid was $170 \mathrm{mg}$. per $100 \mathrm{ml}$. This analysis is typical of chylous fluid. Microscopical examination of smears from the fluid showed a moderate number of lymphocytes and an occasional serosal cell. No malignant neoplastic cells were observed.

Examination of the urine on admission showed no albumin, acetone or sugar. Microscopy showed a large number of epithelial cells with about seven pus cells per high power field (non-catheter specimen).

A blood count gave the following result: haemoglobin, 11.9 g. \%; erythrocytes, 3,560,000 per c.mm.; leucocytes, 8,000 per c.mm. The blood cholesterol level was $185 \mathrm{mg}$. per $100 \mathrm{ml}$., which was $15 \mathrm{mg}$. higher than that of the chylous fluid.

A serum protein estimation gave total proteins, 4.9 g. $\%$; albumin, $2 \cdot 7$ g. \%; globulin, 2.2 g. \%.

Radiological examination of the chest showed nothing abnormal.

The weight of the child dropped to $9 \mathrm{lb} .8 \mathrm{oz}$. after the paracentesis. With the removal of the fluid, the abdomen was easily examined but the liver and spleen were not felt.

Distension of the abdomen reappeared so rapidly that by the fourth day after the paracentesis it was as distended as on admission. Paracentesis was again performed and $20 \mathrm{oz}$. of the same type of fluid were removed. After this removal the fluid seemed to accumulate more slowly. Eighteen days after the second removal of fluid, the procedure was repeated, and on this occasion $24 \mathrm{oz}$. of similarly milky fluid were removed. The serum protein level at this stage had increased to $5 \cdot 3 \mathrm{~g}$. per $100 \mathrm{ml}$. from the previous level of $4.9 \mathrm{~g}$. A further examination of the urine for chyluria was negative. The urine, which was slightly turbid, was water-clear after centrifuging, which suggested that the turbidity was not due to emulsified fat.

After the third paracentesis the child was discharged on the mother's insistence, but was returned to hospital three weeks later with the abdominal distension as gross as before. It had obviously recurred more slowly. A fourth paracentesis was performed, and on this occasion $34 \mathrm{oz}$. of milky fluid were removed. The weight of the infant after the removal of the fluid was $10 \mathrm{lb} .14 \mathrm{oz}$, compared with $91 \mathrm{lb}$. after the first paracentesis 45 days before.
The child was discharged from hospital with instructions to report back at intervals. Eighteen days after the last paracentesis she was brought back with obvious whooping cough complicated by bronchopneumonia. She died on the day of admission.

Necropsy. This was performed by Dr. J. Higginson. The body was that of a Bantu female infant. The right pleural sac had some fibrous adhesions, the left being normal. Both lungs showed moderate congestion with numerous petechial haemorrhages scattered over the pleural surfaces. There was no evidence of dilated lymphatic ducts in the thorax. The pericardium and heart were normal.

The peritoneal sac contained 1 pint of white, milky fluid. The spleen was congested and the kidneys appeared normal, as did the rest of the genito-urinary tract. The liver weighed $150 \mathrm{~g}$. and showed no obvious lesions except for irregular congestion. The gall bladder was healthy. The stomach was normal except for numerous white dilated lacteals along its lesser curvature. The intestinal tract appeared healthy, but several dilated lacteals were noted in the upper portion of the jejunum. There was no dilatation of the cisterna chyli. Histological examination of the lymph channels and nodes around the aorta showed that the channels were widely dilated and filled with lipoid-containing macrophages. A fat stain on the lesser curvature of the stomach showed a very large number of small sudanophil droplets lying in the external portion of the muscle wall and in the subserosal layer. The histological features suggested that there was obstruction of the lymphatic drainage at the level of the diaphragm.

\section{Discussion}

This case was clearly one of chylous ascites in an extremely young infant. The diagnosis could only be made by removing fluid from the peritoneal sac. A total of $104 \mathrm{oz}$. of the milky-white chyle was removed. by four tappings, and in addition another $20 \mathrm{oz}$. were found in the peritoneal sac at necropsy. Notwithstanding the great loss of chyle, the child gained $1 \mathrm{lb} .6 \mathrm{oz}$. in about six weeks.

Various causes have been given to account for the accumulation of chylous fluid in the peritoneal cavity. Busey (1885) cites Morgagni's reference to the cases of Valsalva and Santorino, in which the thoracic duct was blocked by an aneurysm. Busey (1885) also cites Virchow's reference to his case in a newborn calf after a thrombosis of the external jugular vein, occluding the mouth of the thoracic duct. Traumatic rupture of the thoracic duct is a potent cause of the condition. Pure chyle, as it flows from the thoracic duct, is a milky, opaque fluid, slightly alkaline, with a specific gravity between 1007 and 1043, usually not higher than 1025 . About 4\% of the thoracic duct chyle is made up of protein. The fat content varies with the food intake and the protein is made up of serum albumin and globulin. About $10 \%$ of chyle is made up of fat, 
protein and salts, and the rest water. An interesting fact is that in the analysis of the fluid in the case recorded here, the total solids, protein and fat values lay within the same range as human milk (on which this patient was being fed), but the ash, calcium and chloride values were outside recognized limits of breast milk; in addition, lactose, a normal constituent of milk, was absent from the chylous fluid. Rous (1908) mentioned that cases of chylous effusions should exhibit a reduced total lymphocyte count in the blood, as the thoracic duct is the chief pathway of lymphocytes to the blood stream, although small numbers enter directly in the marrow.

Chylous ascites is a condition which must be differentiated from a chyliform effusion which occurs in such conditions as tuberculous peritonitis or peritoneal carcinoma. The analysis of the fluid in the present case conformed to that of a true chylous effusion, and the necropsy findings suggested the presence of a congenital anomaly of the lymphatic drainage of the intestinal tract. Chylous ascites is a very rare condition at any age, but particularly in early infancy. It should be regarded as a symptomcomplex with various aetiological factors at play in different cases. In the case described, it appeared that tappings were required at longer intervals, and that the fluid was accumulating more slowly after each successive paracentesis. The weight of the child improved and also the serum protein level. If the child had not died from whooping cough, it is possible that the condition might have improved with repeated tappings at more infrequent intervals.

\section{Summary}

A case of chylous ascites is described occurring in a Bantu girl in the third month of life. Altogether $104 \mathrm{oz}$. $(3,120 \mathrm{ml}$.$) of this fluid were removed by$ four successive abdominal tappings, and in addition a further $20 \mathrm{oz}$. $(600 \mathrm{ml}$.) were found in the peritoneal cavity at necropsy. On analysis the fluid was shown to resemble true chyle. Histopathology suggested a congenital anomaly of the lymphatic drainage of the intestinal tract as the aetiological factor.

I wish to thank Dr. J. D. Allen, Medical Superintendent, for permission to report this case. Thanks are also due to Dr. J. Higginson for the necropsy and histological examinations, Dr. C. Glynn Williams for his help in attending to this case, Dr. H. Hirsch for laboratory investigations, Mr. S. Kay for helpful advice, Dr. A. R. P. Walker for his analysis of the fluid, and finally to Drs. H. Stein and S. Burgin for their careful case-notes.

\section{REFERENCES}

Busey, S. C. (1885). Amer. J. med. Sci., 90, 373. (1889). Ibid., 98, 563.

Cowie, D. M. (1911). Arch. Pediat., 28, 595.

Kerr, LeG. (1909). N.Y. St. J. Med., 9, 14.

Morgagni (1761). Cited by Busey (1885), p. 374.

Morton (1691). Cited by Cowie.

Nieuwondt, G. and Rozenzweig, R. H. (1892). Brit. med. J., 2, 123.

Rous, F. P. (1908). J. exp. Med., 10, 238.

Schall, L. (1922). Mschr. Kinderheilk., 23, 34.

Scherer, C. A. (1922). Int. Clin., 32 ser., 2, 244.

Valsalva and Santorino. Cited by Busey (1885), p. 374.

Virchow, R. (1854). Virchows Arch., 7, 130. Cited by Busey (1885), p. 375.

Wallis, R. L., and Schölberg, H. A. (1911). Quart. J. Med., 4, 153.

Witt, D. B. (1924). In 'Pediatries', ed. I. A. Abt, vol. 3, p. 400 . Philadelphia. 